\title{
Journal \\ of \\ The Franklin Institute
}

Devoted to Science and the Mechanic Arts

\begin{tabular}{lll}
\hline Vol. 219 & APRIL, 1935 & No. 4 \\
\hline
\end{tabular}

\section{SOLUTION CYCLES AS APPLIED TO STEP-UP TRANS- FORMERS FOR TEMPERATURES.*}

BY

GEORGE GRANGER BROWN, Ph.D.,

Professor of Chemical Engineering, University of Michigan, Ann Arbor, Michigan.

In 1755 Dr. William Cullen produced ice by a vacuum machine. Water at ordinary temperature was placed in an air-tight vessel, the air removed and the pressure reduced by a vacuum pump until the water boiled. The heat necessary for evaporation was absorbed from the water itself and the operation continued until the residual liquid water became so cool that it froze.

Over half a century later in I8Io Sir John Leslie combined Cullen's air pump with a vessel of strong sulfuric acid for absorbing the water vapor, and is reported to have produced from one to one and a half pounds of ice in a single operation. This was probably the first practical application of the fact that a solution will absorb vapor from pure liquid which is at a lower temperature than the solution.

Twelve years later Faraday ${ }^{3}$ reported the results of quantitative investigations of the increase in temperature of a boiling solution above that of the boiling pure solvent. The greatest elevation in boiling observed was about $106^{\circ} \mathrm{F}$. for a potassium salt.

* Presented at the Stated Meeting held Wednesday, December I9, I934.

(Note.-The Franklin Institute is not responsible for the statements and opinions advanced by contributors to the Journal.)

voL. 219 , NO. $1312-28$ 
These properties of solutions were used by Carré and later (I867) by $\mathrm{R}$. Reece in the development of the first solution cycle, the ammonia absorption cycle for refrigeration. Figure I shows the essential features of this cycle in its modern form, which is in wide-spread use today.

FIG. I.

AMMONIA ABSORPTION REFRIGERATION CYCLE

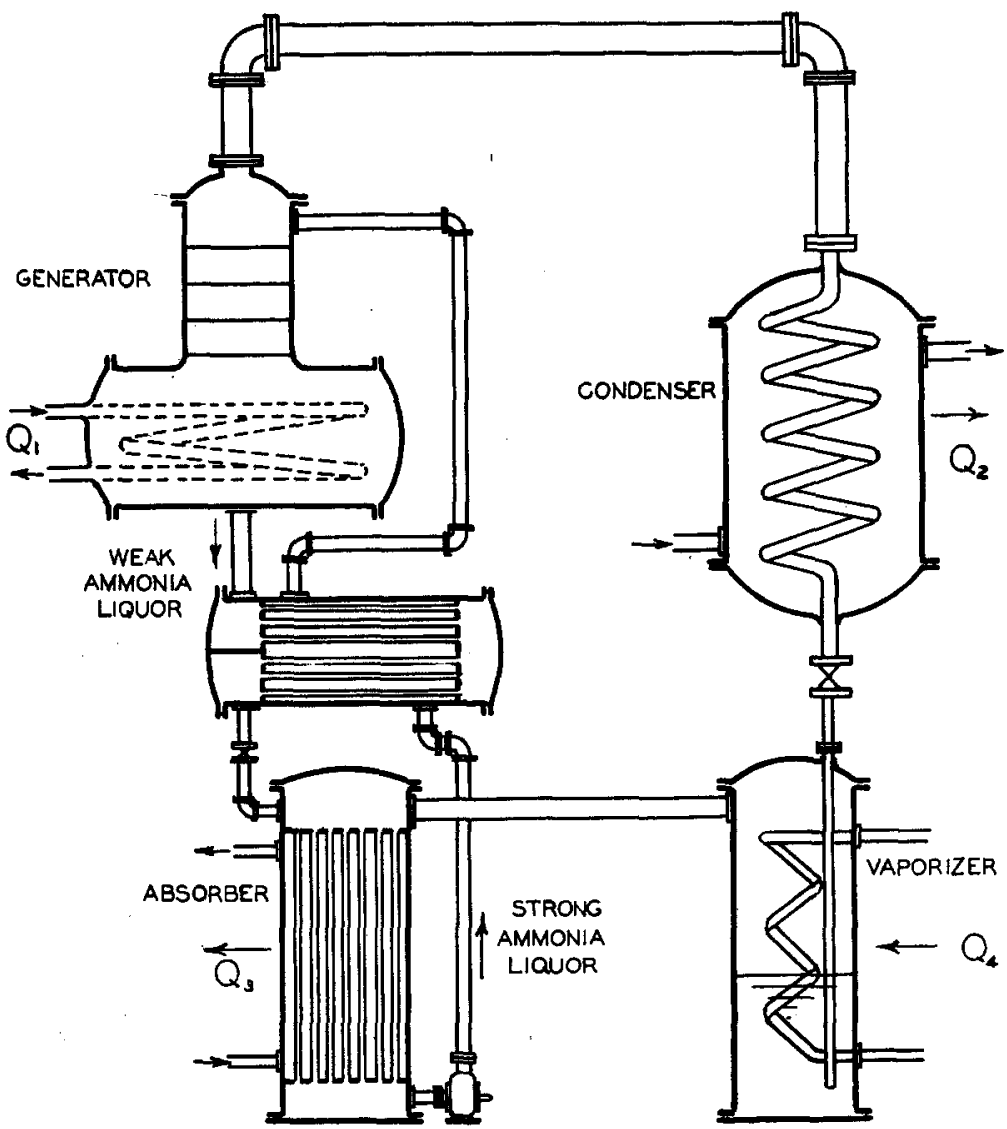

The ammonia absorption refrigeration cycle.

An example of the simple elemental solution vapor compressor incorporated in a refrigeration cycle. Low pressure ammonia vapor is supplied from the vaporizer in the lower right-hand corner to the absorber, and high pressure ammonia vapor is supplied from the top of the generator to the condenser. The solution vapor compressor is operated by heat, $Q_{1}$, supplied to the generator with the rejection of heat, $Q_{3}$, from the absorber. The condenser and vaporizer represent the refrigeration process which absorbs heat, $Q_{4}$, at low temperature in the vaporizer and rejects the heat, $Q_{2}$, at a higher temperature from the condenser. The two processes together make a refrigerating cycle. 
The full significance of Faraday's report on the increase in boiling point of solutions was first appreciated by Spence who reported to the British Association at Exeter in I 869 that the exhaust steam from a steam engine when liberated at atmospheric pressure (temperature $212^{\circ} \mathrm{F}$.) and absorbed in a saline solution having a boiling temperature higher than that of water, would raise the temperature of this saline solution to its own boiling point. This fact is of major importance in the development of solution cycles and is apparently not generally appreciated today.

About the same time (March 12, I872) Emile Lamm ${ }^{7}$ of New Orleans obtained a patent for the operation of a street car with a steam engine; the exhaust steam being absorbed into a solution of calcium chloride or other appropriate material. This solution surrounded a steam generating vessel containing preheated water. As described by Lamm the latent heat removed by the vaporization of water in the steam generator was returned to the steam generator by the condensation of the exhaust steam in the solution; the diluted solution at the end of the run was concentrated by simple evaporation.

A second Spence, ${ }^{17}$ following in his father's footsteps, proposed, in 1874 , to operate a steam engine in a manner similar to that proposed by Lamm, except that caustic soda was used instead of calcium chloride and the solution was to be circulated through the pipes in an ordinary boiler.

A third independent investigator, Honigmann, the proprietor of extensive chemical works at Aix-la-Chapelle in Germany, noticed the high temperature of a kettle of caustic solution caused by a leak in the steam heating coil when inspecting operations in his chemical plant, and built several fireless locomotives on the same principle early in the next decade. Figure 2 illustrates one of the units of this type described by Riedler ${ }^{13}$ who made extensive tests of the Honigmann fireless locomotive in 1883 . Figure 3 is a log of Riedler's experiment 22 in which the engine drew a car with a load of 19 tons up and down the track for one hour, and then two empty cars of total weight $\mathrm{I} 4.5$ tons for the remainder of the run, which lasted for almost four hours on a single filling of caustic of I,620 lbs. containing I 5.7 per cent. water. 
At the end of this time the caustic solution amounted to 2,450 lbs. containing 43.8 per cent. water. During the first hour and 20 minutes, up to the point $A$, steam was used in braking the locomotive at the end of the run; from that point on only the hand brake was used. At the end of 2 hours and

FIG. 2.
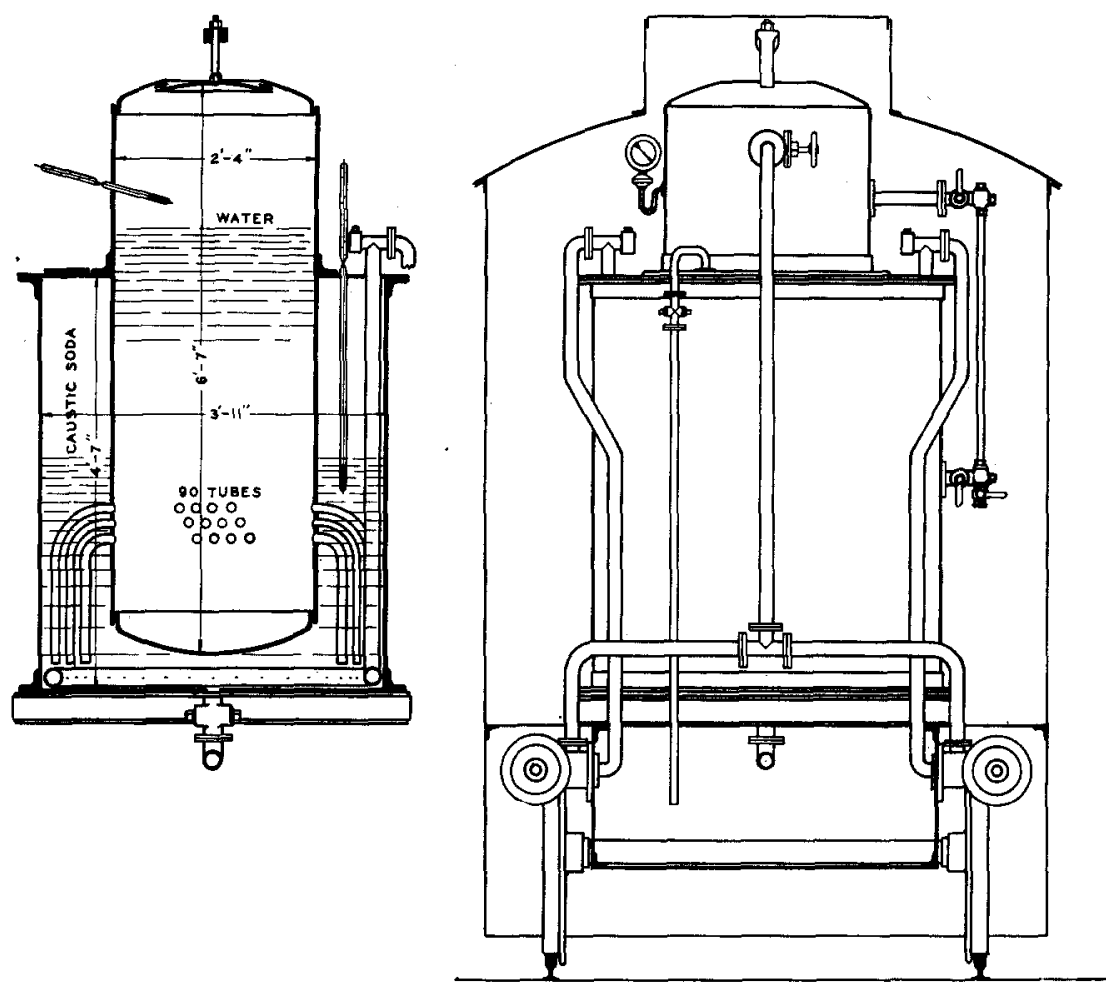

Honigmann's fireless locomotive tested by Professor Riedler.

40 minutes, at the point $D$ on Fig. 3 , the water in the boiler had been reduced to only 3 . 14 inches above the tubes while the caustic level was 14.6 inches above this.

Following this successful experiment numerous commercial installations were made and there was great interest in the technical press until about I 888 when interest seems to have suddenly subsided. 
In all of these operations the reconcentration of the dilute solution was accomplished by simple evaporation. It was quite generally recognized that the thermal efficiency of this process was relatively low, as more coal was consumed in evaporating, or "boiling down" of the solution than is required for evaporation of the same quantity of water under ordinary circumstances. In order to improve the efficiency of the operation Honigmann obtained patents proposing to add a firebox to his "fireless" locomotive and concentrate the solution in a direct fired vessel under the same pressure as employed in the cylinders in the engine, ${ }^{4}$ and to use a double effect evaporator for concentrating the spent solution. ${ }^{4 a}$

FIG. 3.

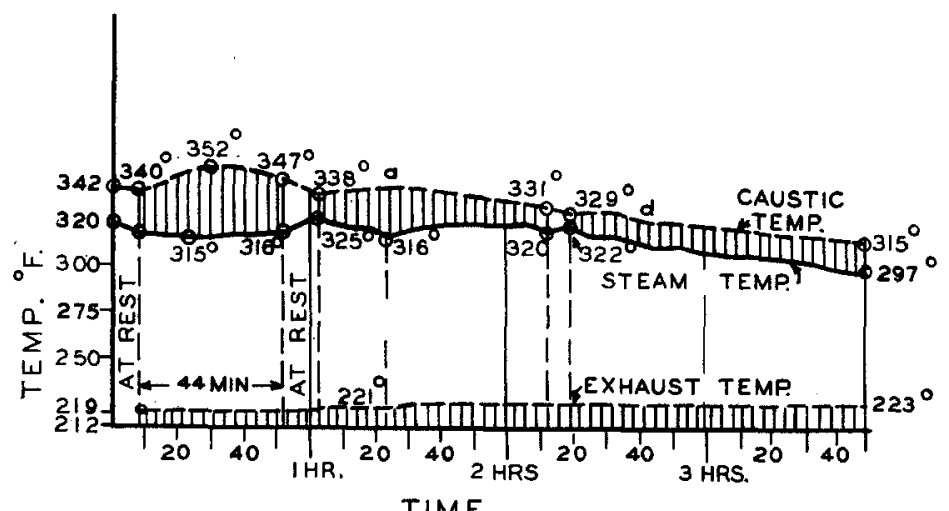

TIME

Log of Riedler's experiment 22 with Honigmann's fireless locomotive as shown in Fig. 2.

The temperature is plotted as a function of time giving the temperature of the caustic solution, the temperature of the steam generated in the boiler, and the temperature of the exhaust steam from the engine as supplied to the caustic solution.

Due, probably, to the low efficiency of these operations the promising start made by Honigmann was apparently abandoned by 1888 and nothing more is heard of such solution cycles until 1908 when Schneevogl ${ }^{14}$ obtained a French patent covering the use of a counter-current heat exchanger between the high temperature concentrated solution flowing from the concentrator to the absorber, and the dilute solution flowing from the absorber to the concentrator. This is an important development from the standpoint of efficiency in such cycles, and is shown in Figs. I, 6, 7, 10. 
An important feature of the use of solutions for the generation of power is the possibility of storing concentrated solution and water without loss in available energy, and generating steam by dilution of the concentrated solution according to the method already discussed. In I9I I this feature was covered by U.S. patent granted to D'EquevilleyMontjustin ${ }^{2}$ who utilized the storage principle for the purpose of operating submarines when submerged by means of a steam engine whose exhaust was absorbed into the solution. The solution was concentrated in an evaporator by steam from the direct-fired boiler when running on the surface.

FIG, 4.

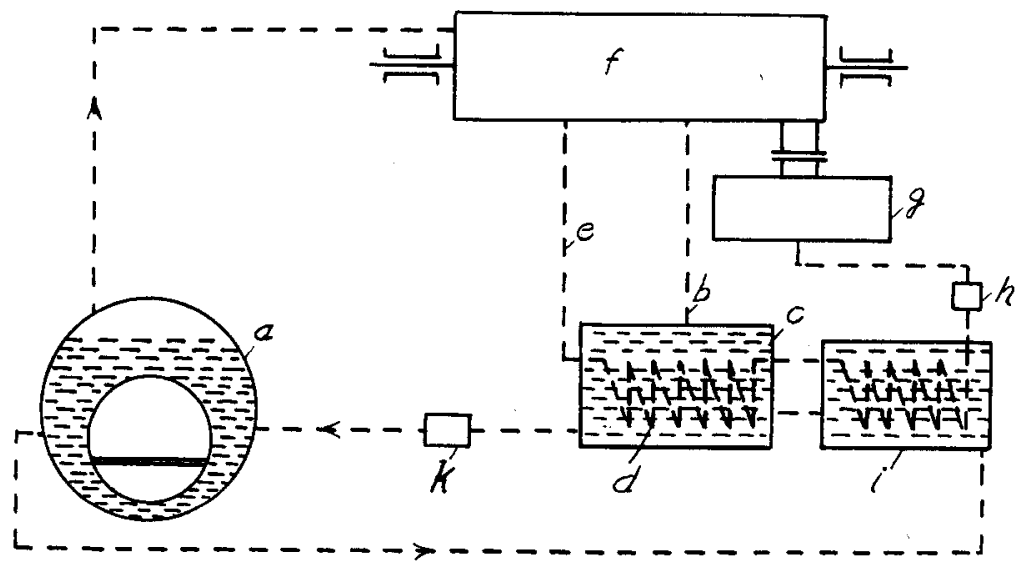

Power solution cycle of Pape.

$A$ is the solution boiler supplying steam to the turbine $F$. An equal quantity of steam is bled from turbine $F$ through line $B$ and absorbed in absorber $C$ where the heat of absorption is used to vaporize water in coil $G$. The steam so formed is fed to turbine $F$ through line $E$, condensed in $G$ and forced by pump $H$ through the coil in $I$ to the vaporizing coil $D$ in absorber $C$. The dilute solution formed in absorber $C$ is forced by pump $K$ into the solution boiler $A$, and the concentrated solution transferred from $A$ to heat exchanger $I$ where it is cooled giving up its sensible heat to the cold condensate from the engine. The cooled solution is then passed through absorber $C$ where it absorbs the steam bled from turbine $F$ through line $B$.

Interest in the use of solutions for the generation of power and for stepping up the temperature in heat cycles began to increase in 1920, particularly in Europe. In that year Pape ${ }^{11}$ obtained a German patent covering the cycle shown in Fig. 4. The following year Koenemann ${ }^{6}$ obtained his first German patent which was followed by others in Austria, Great Britain and in the United States. 
Figure 5 shows the early form of the Koenemann transformer, in which concentrated solution was withdrawn from the lower part of vessel 3 at point 4 and passed into the lower part of vessel 7 through valve 6 . Low pressure vapor enters

\section{FIG. 5.}

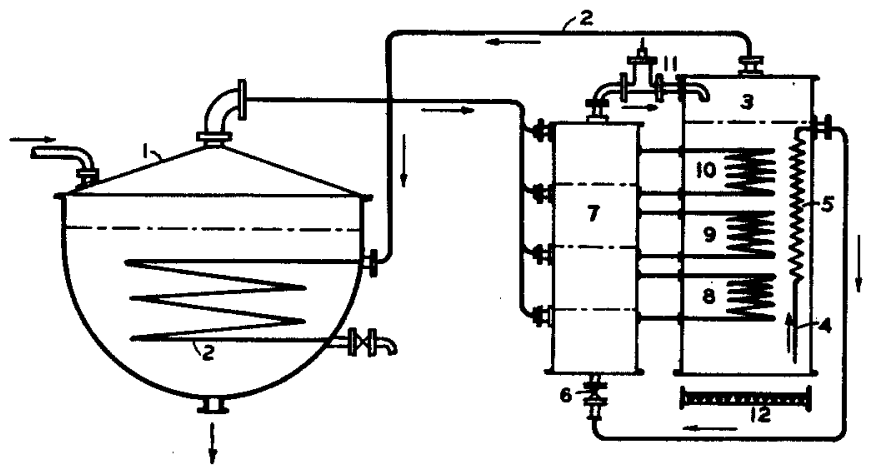

FIG. B

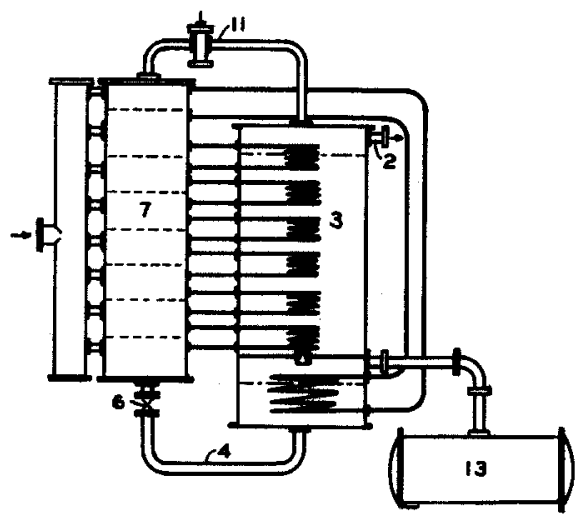

FIG. C

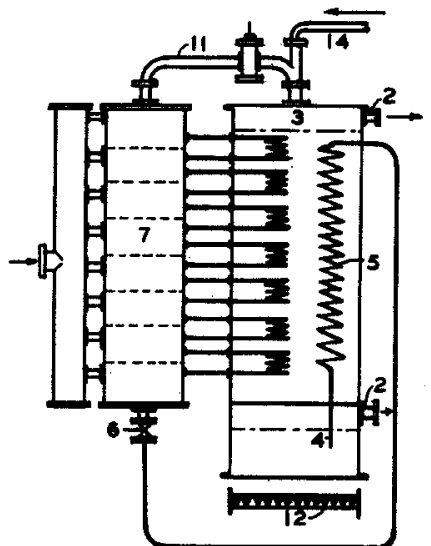

Early form of Koenemann steam pressure transformer as disclosed in British Patent Number 178,829 of January 4, I 923 .

from kettle $\mathrm{r}$ into absorber 7 with dilution of the solution rising therein, the heat effect accompanying the absorption is supplied to concentrator 3 by flowing the diluted solution 
through the heat exchanger coils 8,9 and Io, the dilute solution so formed flows out of the top of absorber 7 through valve II into concentrator 3 wherein the dilute solution becomes progressively more concentrated due to evaporation caused by the hot solution circulated from 7 through coils 8 , 9 and Io, the final concentration being accomplished by the heating element I2. As the solution in 3 adjacent to any coil such as Io is more dilute than the solution circulated in the coil, the pressure in concentrator 3 may be greater than that in absorber 7 , thus supplying steam at a higher temperature through line 2 in return for low pressure low temperature steam supplied to absorber 7 .

A later form of the Koenemann steam pressure transformer described by Lionel S. Marks ${ }^{8}$ is shown in Fig. 6. Low pressure steam is absorbed in the vessel $B$ in a solution of caustic potash at the pressure of the low pressure steam. The heat liberated by this absorption is available at a temperature approximating the boiling point of the solution and is used to boil water in the vessel $C$. The temperature of the water in vessel $C$ approaches that of the solution in $B$ and the pressure of the steam evolved from the water boiler $C$ is greater than that of the low pressure steam supplied to the absorber. To maintain the concentration of the solution in the absorber $B$, the diluted solution is pumped through the heat exchanger $D$ into the concentrator $A$ where the solution is evaporated by means of high pressure steam or other heat source, the steam from this evaporation being combined with the steam from the water boiler making the intermediate pressure steam as used in the process. The concentrated solution formed in the evaporator $A$ is returned through the heat exchanger $D$ and a valve to absorber $B$.

The process shown in Fig. 6 is a solution cycle used for compressing exhaust steam (low pressure steam) to a higher or intermediate pressure for use in a process and may be considered as an alternate method to the mechanical compression of low pressure vapor.

The earliest suggestion of this kind was probably that of Lord Kelvin who proposed in 1852 the use of a compressor (a reversed heat engine) as a means for warming air. He showed that for a small temperature rise the quantity of 
FIG. 6.

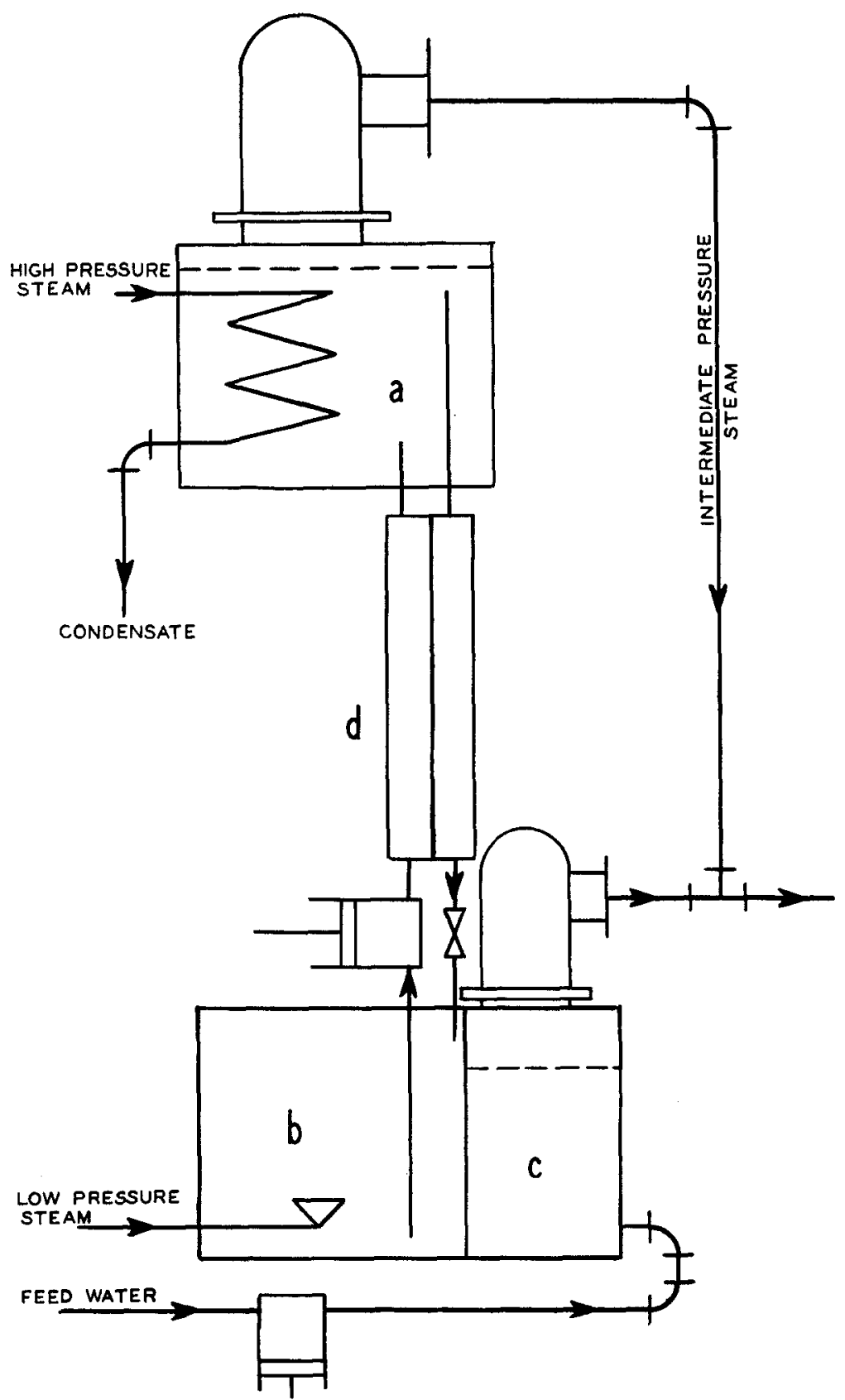

A later form of Koenemann's steam pressure transformer as described by Professor Marks. 
heat required by an efficient heat engine to drive the compressor is less than that necessary for direct heating.

The fundamental principle underlying such an operation is the well-known thermodynamic expression for the maximum quantity of useful available work energy that may be obtained in the ideal (Carnot) heat cycle.

$$
W=\frac{Q_{1}\left(T_{1}-T_{2}\right)}{T_{1}},
$$

in which $W=$ useful available energy or work obtainable from the operation,

$Q_{1}=$ quantity of heat supplied at temperature $T_{1}$,

$T_{1}=$ absolute temperature at which heat quantity $Q_{1}$ is supplied,

$T_{2}=$ absolute temperature at which heat is discarded or rejected from the heat cycle.

Similarly for the minimum quantity of available energy or work that must be supplied in order to increase the temperature of heat, as in the vapor compressor,

$$
\Delta G=-W=\frac{Q_{1}\left(T_{2}-T_{1}\right)}{T_{1}},
$$

in which $\Delta G$ or $-W=$ the available energy or minimum work that must be put into the operation or cycle in order to increase the temperature of the heat quantity $Q_{1}$.

If the required elevation in temperature $\left(T_{2}-T_{1}\right)$ is small such as $20^{\circ} \mathrm{F}$. the work required $(-W)$ is small for the delivery of a relatively large quantity of heat $Q_{2}$ (such as I, IOO B.t.u.) at temperature $T_{2}\left(90^{\circ} \mathrm{F}\right.$. or $550^{\circ} \mathrm{R}$.),

$$
-W=\frac{Q_{2}}{T_{2}}\left(T_{2}-T_{1}\right)=2(20)=4 \text { o B.t.u. }
$$

If the heat engine cycle operates between the temperature limits of $230^{\circ} \mathrm{F}$. and $90^{\circ} \mathrm{F}$. the quantity of heat $Q_{1}$ necessary at $230^{\circ} \mathrm{F}$. to deliver 40 B.t.u. of available energy or work is

$$
Q_{1}=\frac{T_{1} W}{T_{1}-T_{2}}=\frac{690 \times 40}{120}=230 \text { B.t.u. }
$$


Therefore only 230 B.t.u. are required by an ideal cycle to deliver I,IOO B.t.u. under these conditions. Even with the low efficiency of 70 per cent. in each, the engine and the compressor, giving an overall efficiency of about 50 per cent., 500 B.t.u. supplied to the heat power cycle is more than adequate to deliver I, Ioo B.t.u. under these conditions.

Since an overall efficiency of 50 per cent. is easily attained in the solution cycle such as the Koenemann vapor compressor, the possible economic advantage in the use of such equipment under such conditions may be appreciated.

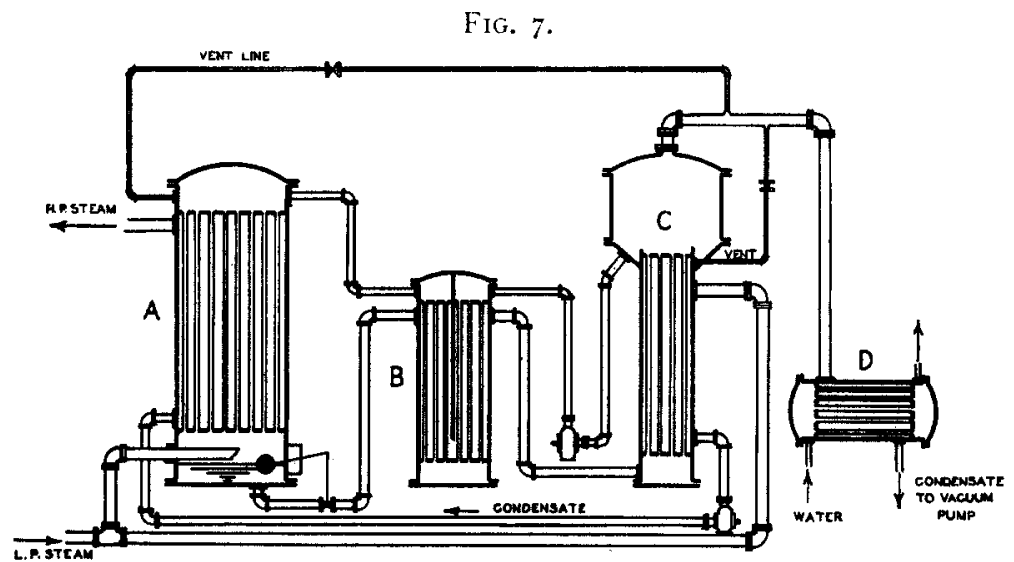

Solution steam pressure transformer for separation.

Low pressure steam is supplied to the absorber through the line at the lower left corner of the figure, and is absorbed in absorber $A$ by the concentrated solution flowing from the heat exchanger $B$ into the top of absorber $A$. The heat of this absorption is used to vaporize water supplied to the space outside the tubes of the absorber $A$ at a higher pressure than the low pressure steam. The high pressure steam so formed is withdrawn from the upper left-hand side of the absorber as indicated. The dilute solution formed in the absorber passes out the bottom of the absorber through a flow control valve into the heat exchanger $B$ in counter-current heat exchange with the concentrated solution flowing to the absorber. The preheated dilute solution then enters the bottom of the concentrator or evaporator $C$ where the steam absorbed in absorber $A$ is again liberated at a lower pressure and condensed in condenser $D$. The concentrated solution so formed in evaporator $C$ is picked up by the pump and forced through the counter-flow heat exchanger to the absorber. In the case considered by Mr. A. M. Selvey the heat of condensation of the steam from evaporator $C$ was used to heat water in the condenser $D$ for use in the laundry and club.

A different arrangement of apparatus but applying similar principles was suggested by Praetorius, and is of interest as it provides a means for the compression of vapor without requiring any other source of heat than the low pressure vapor itself. Figure 7 is a diagrammatic representation of such an arrangement as it might be constructed.

Overlapping the development of the Koenemann steam pressure transformer other advances have been made in

VOL. 2I9, No. I3I2-29 
Europe, and in this country, notably by $W \mathrm{~m}$. H. Sellew. A theoretical treatment of the method of computing the performance of such solution cycles, based on the thermodynamic properties of the solution used, was first presented by Frederick Merkel ${ }^{9}$ of Dresden. Because of lack of data concerning the properties of caustic potash and soda, Merkel was obliged to make simplifying assumptions in the construction of his enthalpy-concentration chart.

Merkel's pioneer work in the development of these charts has been continued in Germany by Bošnjakovic ${ }^{1}$ and by W. L. McCabe ${ }^{10}$ in this country.

The enthalpy-concentration chart serves the same purpose for solutions as the well-known steam tables and Mollier diagram for steam. When the enthalpy-concentration chart uses the same reference state as the steam tables, the two may be used in conjunction to compute the heat quantities and operations of the solution cycle.

A satisfactory method for computing the operation of a solution thermo-compressor, which has been verified by preliminary tests on small units, is demonstrated in the following calculation for a Koenemann steam pressure transformer using the enthalpy-concentration chart ${ }^{10}$ for caustic soda (Fig. 8) and Dühring plot (Fig. 9) according to McCabe, ${ }^{10}$ and the Keenan ${ }^{5}$ steam tables.

Using the arrangement shown in Fig. 7, with low pressure steam supplied at 20 lbs. per sq. in. abs. to deliver high pressure steam at 49 lbs. per sq. in. abs.,

Operating Conditions, Cycle, Fig. 7 :

Condensing temperature of 1.p. $20 \mathrm{lb}$. steam

Temperature drop from steam to solution

Temperature of concentrated solution in concentrator

Temperature of saturated h.p. steam (49 lbs.)

Temperature drop absorber to boiling water

Temperature of solution in absorber

Allowed boiling temp. dilute solution 20 p.s.i. abs.

$=228^{\circ} \mathrm{F}$.

$=30$

$=198^{\circ} \mathrm{F}$.

$=280^{\circ} \mathrm{F}$.

$=25$

$=305$

$=315$

Concentration dilute solution in absorber (Fig. 9)

$=52.5 \%$

Assume pressure in concentrator

Then concentrated solution in concentrator

Temperature difference cold end (concentrator) of heat exchanger

Temperature of $52.5 \%$ solution entering concentrator

$=\quad$ I.o p.s.i

$=60 \%$

$=30^{\circ} \mathrm{F}$.

$=228^{\circ} \mathrm{F}$. 
FIG, 8.

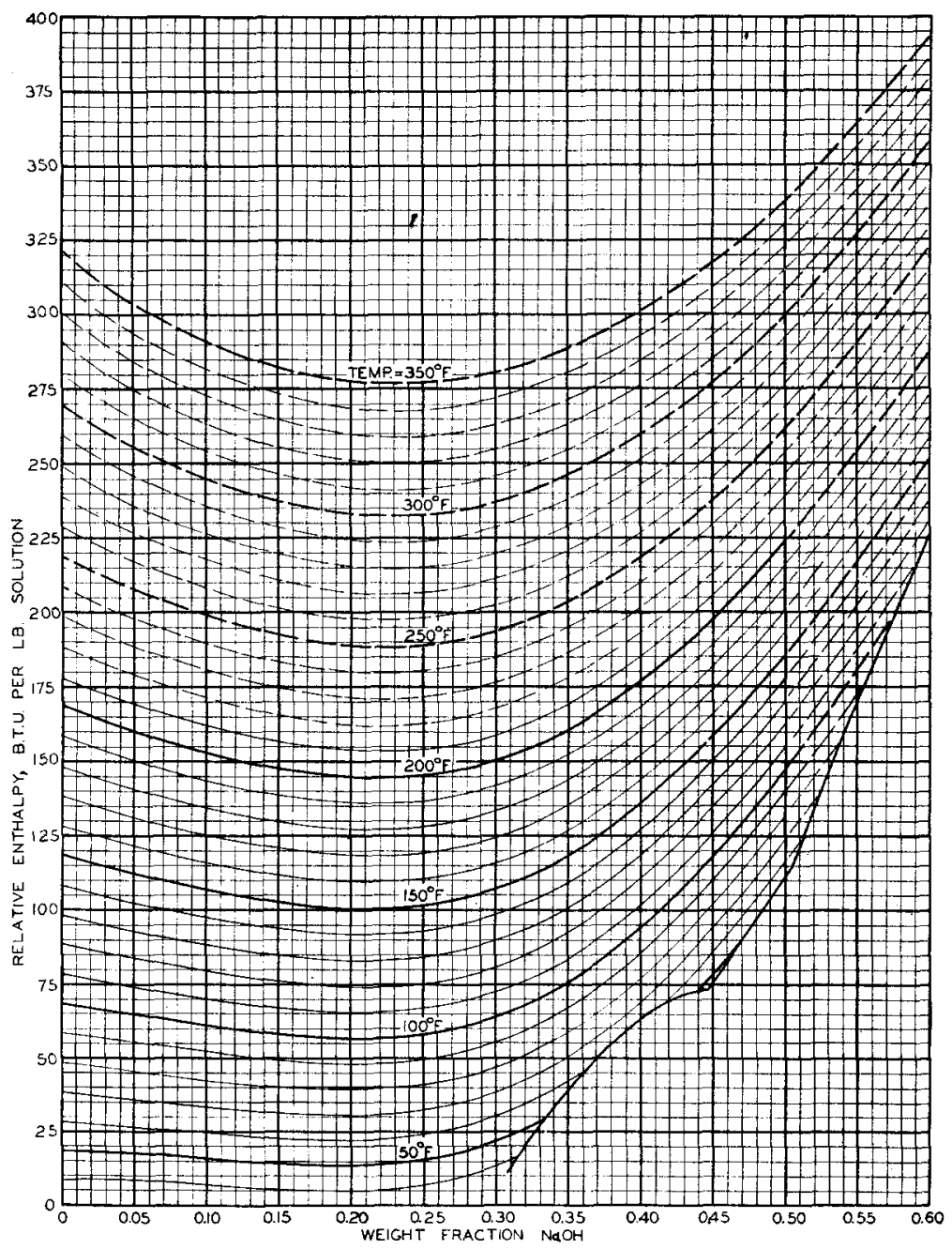

Enthalpy ("heat content") of a lb. of sodium hydroxide water solution as referred to pure liquid water at $32^{\circ} \mathrm{F}$. plotted as a function of the concentration of the solution.

These heat quantities may be used directly in coniunction with the usual steam tables to determine the heat effects of evaporation, absorption, or changes in temperature of the solution within the cycle. 
FIG. 9 .

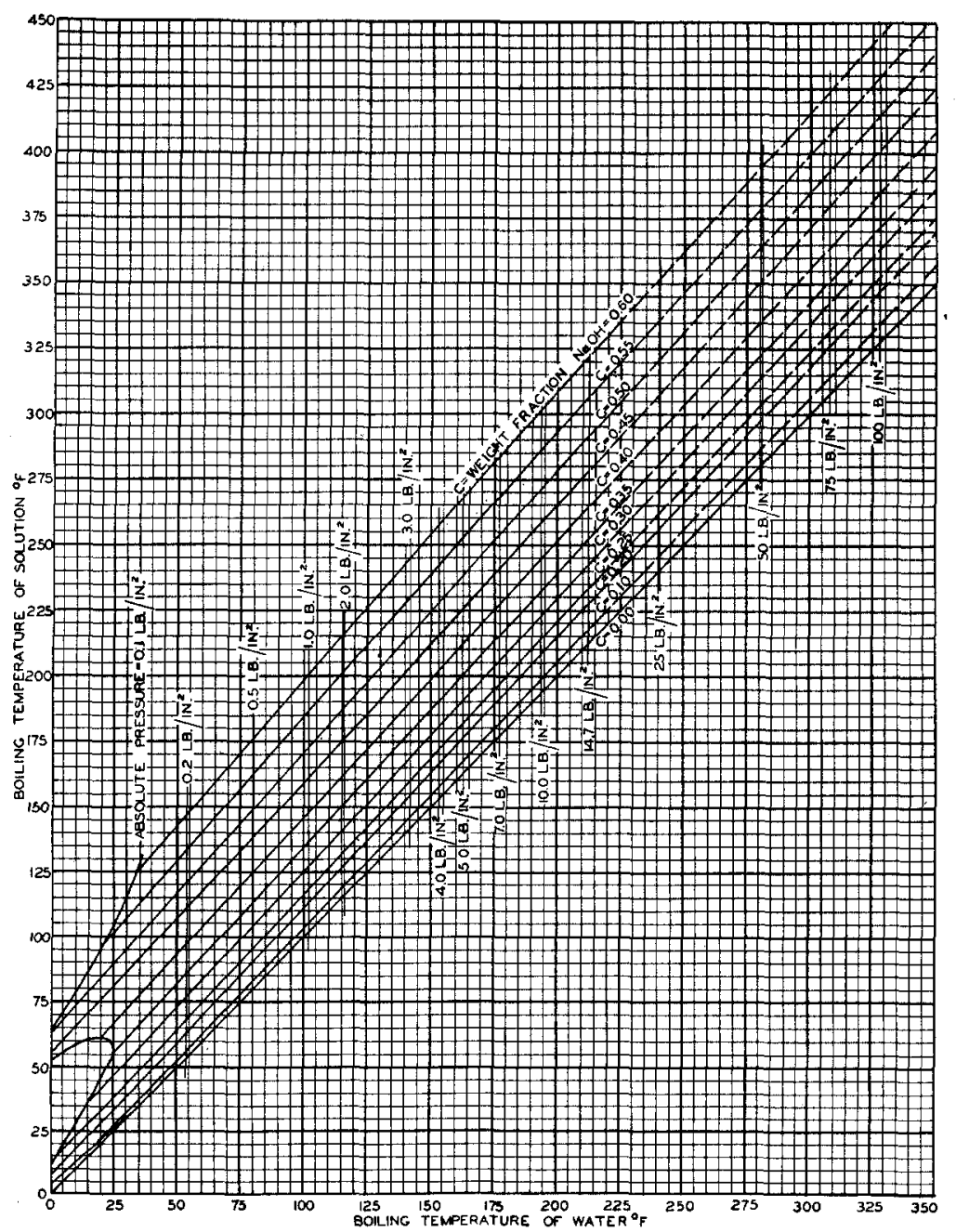

Duhring plot of caustic soda water solution.

The temperature at which the solution boils is plotted as a function of the temperature at which pure water boils when under the same pressure. This is a most convenient way of leveling and comparing the boiling points of solutions and solvents. 
Specific Enthalpies (per lb.):

Steam at 20 p.s.i............. I, 156 B.t.u. (saturated)

Steam at 49 p.s.i. . . . . . . .

Steam at I p.s.i............. r,I48.9 B.t.u. @ I98 F.

$60 \%$ solution @ $198^{\circ} \mathrm{F} .=285$ B.t.u.; @ 290 $0^{\circ} \mathrm{F} .=35^{2}$

$52.5 \%$ solution @ 228 $8^{\circ} \mathrm{F} .=25^{8}$ B.t.u.; @ 31 $5^{\circ} \mathrm{F} .=316.8$

Heat Balances on Basis of i Lb. Low Pressure Steam into Absorber. Heat Balance Around Absorber and Heat Exchanger

Quantity $52.5 \%$ solution leaving absorber $\frac{60}{60-52.5}=8 \mathrm{lb}$.

Quantity $60 \%$ solution entering absorber $\quad=7 \mathrm{lb}$.

$$
\text { Heat In Heat Out }
$$

I\# Steam 20 p.s.i. $=$ I, 156 B.t.u. Delivered to boiler $=\mathrm{I}, 087$ B.t.u. $7 \# 60 \%$ sol. @ $198^{\circ} \mathrm{F} .=1,995 \quad 8 \# 52.5 \%$ sol. @ $228^{\circ} \mathrm{F} .=2,064$

$$
3,15 \mathrm{I} \quad 3,15 \mathrm{I}
$$

$\frac{\mathrm{I}, 087}{\mathrm{II}, 73.2-67.9}=0.98 \mathrm{lb}$. h.p. steam per lb. 1.p. steam to absorber.

Heat Balance A round Concentrator:

\section{Heat In}

8 82.5\% sol. at $228^{\circ} \mathrm{F} . \quad=2,064$

By condensing 20 p.s.i. steam $=1,079.9$

$$
3,143.9
$$

Heat Out

$$
\begin{array}{ll}
7 \# 60 \% \text { sol. @ } 198^{\circ} \mathrm{F} . & =\mathrm{r}, 995 \\
\mathrm{I} \text { Steam } @ 198^{\circ} \mathrm{F} . \text { I p.s.i. }= & \frac{1,148.9}{3,143.9}
\end{array}
$$

$\frac{\mathrm{I}, 079.9}{959.9}=\mathrm{I} . \mathrm{I} 25 \mathrm{lbs}$. sat. steam at 20 p.s.i. to concentrator

$\frac{\mathrm{I}+\mathrm{I} . \mathrm{I} 25}{.98}=2.167 \mathrm{lbs}$. total low pressure steam (20 p.s.i.) to deliver I lb.

h.p. steam (49 p.s.i.). Allowing $5 \%$ for radiation, about $2.275 \mathrm{lbs}$. of p.s.i. steam required for I $\mathrm{lb} .49$ p.s.i. steam, or an efficiency of conversion of $44 \%$.

Heat Balance Around Heat Exchanger:

$$
\text { In }
$$

8\# $52.5 \%$ solution @ 31 $5^{\circ} \mathrm{F} .=2.534 .4$ B.t.u. 7 \# $60 \%$ solution @ 198

$$
=\frac{1,995}{4,529 \cdot 4}
$$

Out

$$
\begin{aligned}
@, 228^{\circ} \mathrm{F} . & =2,064 \\
\left(290^{\circ} \mathrm{F} .\right. & =\frac{2,465 \cdot 4}{4,529 \cdot 4}
\end{aligned}
$$

The practical application of such a solution cycle (Fig. 7) has been carefully studied by A. M. Selvey ${ }^{16}$ of the Detroit Edison Co: who makes the following comments.

The Koenemann cycle has, however, two useful applications in the lowpressure low-temperature non-corrosive field. It can elevate low-pressure steam to a medium pressure by means of the addition of high-pressure steam, called combination, or it can elevate medium-pressure steam to a higher pressure.

This latter is called separation because the increased availability is obtained by rejecting a portion of the supply as exhaust steam. 
Combination is an inexpensive method of increasing the availability of exhaust steam or increasing the steam pressure to permit the addition of several stages of evaporation to chemical manufacturing processes. The addition of one high-pressure boiler and the use of a Koenemann transformer may be a substitute for adding a number of low-pressure boilers.

Separation also has an interesting practical application in the production of relatively high-pressure steam when medium-pressure steam is the only available source of heat. This is obtained as in Fig. 7 by reversing the usual positions of the absorber and concentrator.

A comparison was made by the writer of the performance of a pressure transformer and an electrically-driven compressor for increasing district-heating steam pressure at 45 p.s.i. abs. to 95 p.s.i. for use in certain laundry equipment operating at a high temperature corresponding to the increased saturation pressure. The laundry considered in the writer's study was situated in an athletic-club building where it was not convenient to install a boiler plant with a twelve to fifteen story chimney, and where the only source of steam was the district-heating main in the street. The compressor was installed as the most satisfactory means of raising the steam pressure. The study which considered the hypothetical operation of a Koenemann transformer in place of the compressor, showed that the transformer was economical only when part or all of the rejected low-pressure exhaust steam could be used for heating water for the laundry and club use. Based upon curves indicating the probable hourly variation during the day of the use of steam and hot water, and assuming that all lowpressure exhaust steam could be utilized for water heating, the operation of the transformer showed a possible annual operating saving of 50.3 per cent. exclusive of capital charges.

The possibilities of the Koenemann steam-pressure transformer appear to warrant additional chemical and metallurgical research.

William H. Sellew was apparently the first, at least in this country, to appreciate the full significance of the Carnot principle as expressed in equation (I) as applied to solution cycles. The quantity of work, $W$, indicated by equation $\mathbf{I}$ is the maximum which may be obtained only under certain definite ideal conditions, 3 in number:

I. All of the heat that is received by the system that is converting heat into work must be received at $T_{1}$. No heat can be allowed to enter at any lower temperature.

2. All of the heat that leaves the system must leave at the temperature $T_{2}$. No heat must be allowed to leave at a higher temperature.

3. Every step or process in the operation or cycle must take place reversibly. This requirement is somewhat more difficult to visualize and much more difficult to approach in practice than the other two, as it rules out friction, throttling, 
flashing, the addition of a cool fluid to a warmer one, temperature heads in heat transfer and all other operations that do not take place under equilibrium or reversible conditions. Although this requirement can be approached, it is impossible of complete realization in any practical operation.

These three requirements are necessary and sufficient for realization of the Carnot efficiency. It is not necessary to postulate any particular type of equipment, any particular kind of cycle, or any particular working substance. Within the system other forms of energy may be involved, such as electrical energy, or chemical energy, provided only that these three requirements are met.

In the Rankine (steam engine) cycle using superheated steam, the heat enters the cycle largely at the saturation temperature, or the temperature at which the water vaporizes. The heat in the superheat is a relatively small part of the total heat entering the cycle. In order to raise the saturation temperature, increased pressures as high as 2,000 to 3,200 lbs. per sq. in. are being used. By the proper use of aqueous solutions, all of the heat enters the cycle at the temperature of superheated steam, because the vapor formed by boiling a solution is, per se, "superheated," i.e. at a temperature above boiling water at the same pressure. Furthermore the solution may be so chosen as to have a high boiling point at moderate pressures, thereby gaining the efficiency of high pressure cycles or of combined mercury-steam cycles.

The use of solution cycles makes possible the fulfillment of the first two conditions for attaining the Carnot efficiency in a flexible and convenient manner. It remains, therefore, only to limit the irreversible processes within the cycle to attain an efficiency that will approach the Carnot efficiency as calculated from the two terminal temperatures. By heat exchange, bleeding of prime movers, and absorption of vapors, and other devices not possible to the one compound cycle, irreversible processes can be reduced to a minimum or as far as economically justified.

For heating and cooling operations heat $Q_{1}$ supplied at a high temperature $T_{1}$ to one process which rejects heat $Q_{2}$ at a lower temperature $T_{2}$ may be used for operating a second process which absorbs heat $Q_{4}$ at a low temperature $T_{4}$ and 
rejects as heat $Q_{3}$ at a higher temperature $T_{3}$, the heat $Q_{4}$ plus the necessary available energy $\Delta G$ which in this case is supplied as $W$ from the first process.

An energy balance around such an operation clearly indicates

$$
Q_{1}+Q_{4}=Q_{2}+Q_{3}
$$

If the operations are conducted in a reversible manner so that equation ( $\mathrm{I}$ ) may be applied,

$$
\begin{aligned}
Q_{1} \frac{T_{1}-T_{2}}{T_{1}} & =\frac{T_{3}-T_{4}}{T_{3}} Q_{3}=\frac{T_{3}-T_{4}}{T_{4}} Q_{4}, \\
\frac{Q_{3}}{Q_{1}} & =\frac{T_{1}-T_{2}}{T_{1}} \times \frac{T_{3}}{T_{3}-T_{4}}, \\
\frac{Q_{4}}{Q_{1}} & =\frac{T_{1}-T_{2}}{T_{1}} \times \frac{T_{4}}{T_{3}-T_{4}} .
\end{aligned}
$$

Equation (3) expresses the ideal (Carnot efficiency) coefficient of performance for a solution heating cycle when $Q_{2}$ is not available for heating.

$$
\frac{Q_{3}}{Q_{1}}=\frac{\text { heat delivered for heating }}{\text { heat supplied for operation }} .
$$

Equation (4) expresses the ideal coefficient of performance for a solution refrigerating cycle.

$$
\frac{Q_{4}}{Q_{1}}=\frac{\text { heat absorbed for refrigeration }}{\text { heat supplied for operation }} .
$$

If $T_{2}$ is the same as $T_{3}$ as is frequently the case, the heat quantity $Q_{2}$ is added to $Q_{3}$ for the heating operation, and the actual coefficient of performance (C.P.) becomes

or

$$
\frac{Q_{3}+Q_{2}}{Q_{1}}=\frac{Q_{1}+Q_{4}}{Q_{1}}=\mathrm{I}+\frac{Q_{4}}{Q_{1}}
$$

$$
\text { C.P.Heating }=I+\text { C.P.Rerrigeration. }
$$

Since the quantity of cooling water required by an air conditioning or refrigerating cycle is frequently an important factor, the equivalent term total heat rejected $\left(Q_{2}+Q_{3}\right)$ per unit of refrigeration is of interest, 


$$
\frac{Q_{2}+Q_{3}}{Q_{4}}=\frac{Q_{1}+Q_{4}}{Q_{4}}=\frac{Q_{1}}{Q_{4}}+\frac{Q_{4}}{Q_{4}}=\frac{\mathrm{I}}{\text { C.P. }}+\mathrm{I} .
$$

Equation (6) gives the quantity of heat rejected from a solution refrigeration cycle for a unit of heat absorbed at the low temperature. This heat quantity is proportional to the quantity of cooling water required only if all heat is rejected isothermally at $T_{2}=T_{3}$ as this was assumed in deriving the equation.

In the elemental refrigeration cycle shown in Fig. I, under the same conditions $\left(T_{2}=T_{3}\right)$, the ideal coefficient of performance is

$$
\frac{Q_{4}}{Q_{1}}=\frac{T_{1}-T_{2}}{T_{1}} \times \frac{T_{4}}{T_{2}-T_{4}} .
$$

If, as a very rough approximation, the solution is assumed to follow the Ramsay and Young Rule ${ }^{12}$ for boiling temperatures of solution and solvent (water) when under the same pressure,

$$
\left.\frac{T_{S}}{T_{W}}=\frac{T_{1}}{T_{2}}=\frac{T_{3}}{T_{4}}=\frac{T_{2}}{T_{4}}=k \text { (a constant }\right),
$$

where $T_{S}=$ absolute boiling point of solution,

$T_{W}=$ absolute boiling point of pure volatile component at the same pressure.

Then by substitution from equation (8), equation (7) becomes

$$
\frac{Q_{4}}{Q_{1}}=\frac{1}{k}
$$

Although this expression is not rigorous for any known solution it helps to clarify the relationships between the coefficient of performance in elemental refrigeration cycles such as Fig. I, and the properties of the solution used. In all such cases $k$, which corresponds to the slope of the line in Fig. 9, is greater than unity and the coefficient of performance for the simple refrigeration cycle of Fig. I using such a solution must be less than unity. If, however, a solution is employed for which $T_{S} / T_{W}$ is less at low pressure than at high pressure a higher coefficient of performance can be obtained because $T_{1}$, the temperature of heat input, is thereby raised. 
Equations (4) and (5) show that, for constant $T_{2}, T_{3}$ and $T_{4}$, high coefficients of performance are dependent upon high temperatures of heat supply $\left(T_{1}\right)$. Therefore any convenient type of solution may be used to attain high efficiency provided the cycle is so constructed as to absorb heat at a high temperature $\left(T_{1}\right)$ regardless of the vapor pressure characteristics of the solution used.

The possibility of high temperature heat input with all of the heat entering the cycle at the maximum temperature is a most important characteristic of solution cycles which has only recently been appreciated.

FIG, IO.

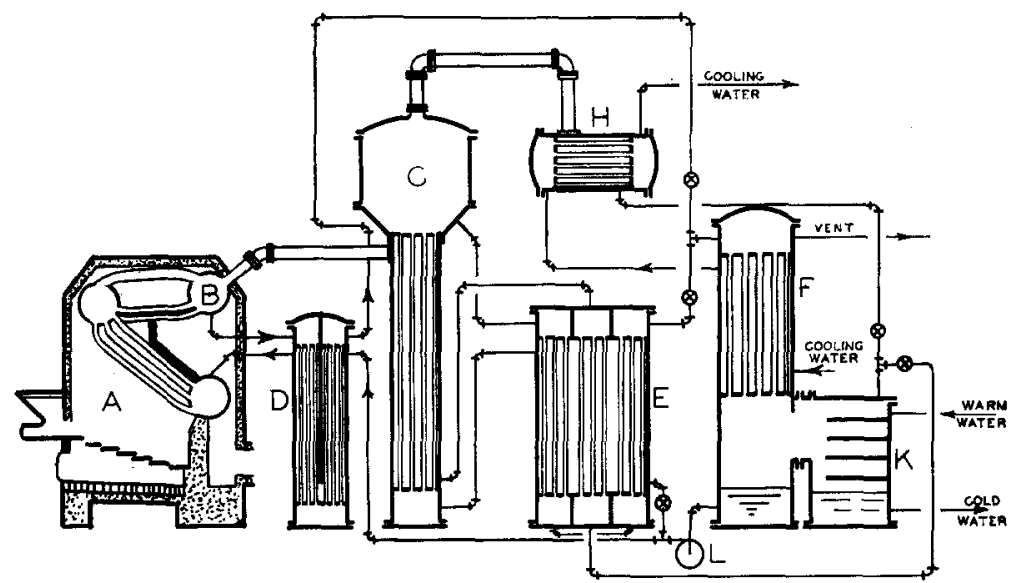

Direct-fired double-effect concentration solution cycle as applied to the refrigerating of water as required for air-conditioning units.

Warm water supplied to the vaporizer $K$ is cooled by vaporization of part of the water and the refrigerated water so formed is removed as cold water. The low pressure water vapor formed in the vaporizer $K$ is absorbed in absorber $F$ by the concentrated solution entering the top of absorber $F$ from the two counter-flow heat exchangers. The dilute solution so formed is collected at the bottom of the absorber, picked up by pump $L$ and forced through the heat exchangers $E$ and $D$ outside the tube to the concentrators $C$ and $A B$. The vapor formed from concentrating this solution in $A B$ is used to boil solutions in concentrator $C$ and the condensate so formed passed through the counter-flow heat exchanger $E$ to the top of vaporizer $K$. The concentrated solution withdrawn from $B$ passes through the heat exchanger $D$ to the top of absorber $F$. The vapor formed in concentrator $C$ is condensed in condenser $H$ and brought to the top of the vaporizer $K$. The concentrated solution formed in concentrator $C$ flows through the heat exchanger $E$ and enters the top of absorber $F$. The heat of absorption of the low pressure vapor in absorber $F$ is transferred to cooling water flowing outside the tubes in the absorber. This cooling water may then flow through condenser $H$ in series with absorber $F$, or a fresh supply of cooling water may flow to condenser $H$ as desired.

Sellew ${ }^{15}$ obtains a high temperature of heat input and corresponding high efficiency by the use of multiple effect concentration and, when desired, multiple effect absorption. Figure Io shows the flow diagram of such a unit used for 
refrigerating water as is required for air conditioning units. The first concentrator, $A$, is shown as direct fired but could be a steam heated evaporator such as the second effect $C$ if desired. The following calculations representing efficient conditions will explain the operation of such a cycle.

Operating Conditions, Cycle, Fig. Io:

Cold water to be cooled to $40^{\circ} \mathrm{F}$. (corresponding pressure 0.1217 p.s.i.)

Cooling water available at $70^{\circ} \mathrm{F}$. to condense vapors at $90^{\circ} \mathrm{F}$. and 0.698 p.s.i. Actual solution temperature in absorber $F \ldots \ldots \ldots \ldots \ldots \ldots 90^{\circ} \mathrm{F}$. Temperature difference to allow for departure from equilibrium... $7^{\circ} \mathrm{F}$. Theoretical boiling temperature of solution in absorber $F 97^{\circ} \mathrm{F}$ at $0.12 \mathrm{I} 7$ p.s.i. Corresponding concentration of dilute solution from absorber $F \ldots 45 \%$ Concentrated solution from evaporator C. \& B ............ $50 \%$ Boiling temperature $50 \%$ solution under 0.698 p.s.i. in $C \ldots \ldots 162^{\circ} \mathrm{F}$. Allowed temperature drop over heating surface in $\mathrm{C} \ldots \ldots \ldots \ldots 20^{\circ} \mathrm{F}$. Condensing temperature steam in evaporator $C \mathrm{I} 82^{\circ} \mathrm{F}$. at 7.849 p.s.i.

Boiling temperature $50 \%$ solution under 7.849 p.s.i. in $A \ldots \ldots 260^{\circ} \mathrm{F}$. Cold end temperature difference heat exchangers $D$ and $E \ldots \ldots, 15^{\circ} \mathrm{F}$. Temperature of $50 \%$ solution and condensate from $D$ and $E \ldots \ldots 105^{\circ} \mathrm{F}$. Specific Enthalpies (per lb.):

Steam 7.849 p.s.i.

Water condensate

Steam 0.698 p.s.i.

Steam 0.I2I 7 p.s.i.

From chart (Fig. 8)
I,I38 B.t.u. (saturated) 73 B.t.u. at $105^{\circ} \mathrm{F}$. I,095 B.t.u. (saturated) I,077 B.t.u. (saturated)
I, I75 B.t.u. at $260^{\circ} \mathrm{F}$. 58 B.t.u. at $90^{\circ} \mathrm{F}$. $\mathrm{I}, \mathrm{I} 3^{2}$ B.t.u. at $\mathrm{I} 62^{\circ} \mathrm{F}$.

Flow Quantities:

$$
\begin{aligned}
& 50 \% \text { Solution at } 105^{\circ} \mathrm{F} . \text { I } 47 \text { B.t.u. } \\
& 45 \% \text { Solution at } 90^{\circ} \text { F. I07 B.t.u. }
\end{aligned}
$$

For I lb. evaporation, $50 \%$ solution $=\frac{0.45}{.50-.45}=9 \mathrm{lb}$.

$$
45 \% \text { solution }=\frac{.50}{.50-.45}=10 \mathrm{lb} \text {. }
$$

FOR I LB. EVAPORATION IN C:

Heat Balance Around $C$ and $E$ :

\section{Heat In}

Io lbs. $45 \%$ sol at $90^{\circ} \mathrm{F}$.

$$
=10 \times 107
$$

By condensing steam
Heat Out

I lb. steam $162^{\circ} \mathrm{F}$.

$$
\begin{aligned}
& =\mathrm{I}, 070 \quad 0.698 \text { p.s.i. } \quad=\mathrm{r}, \mathrm{I} 32 \text { B.t.u. } \\
& =\frac{\mathrm{r}, 385}{2,455} 9 \text { lb. } 50 \% \text { sol. at } 105^{\circ} \mathrm{F} .=\frac{\mathrm{1,323}}{2,455} \text { B.t.u. }
\end{aligned}
$$

Lbs. steam from $A=\frac{1,3^{8} 5}{1,175-73}=1.26$

$50 \%$ solution from $A=\mathrm{I} .26 \times 9=\mathrm{II} .34 ; 45 \%$ solution to $D$ I.26 $\times$ Io $=12.6$ 
Heat Balance Around $A$ and $D$ :

I $2.6 \mathrm{lbs} .45 \%$ sol. at

\section{Heat In}

$90^{\circ} \mathrm{F}$.

Heat supplied as $Q_{1}$ at $T_{1}$

$$
=\mathrm{I}, 348 \text { B.t.u. }
$$

$$
=\frac{I, 800}{3, I 48}
$$

Heat Out

I.26 steam at $260^{\circ} \mathrm{F} .=1,48 \mathrm{I}$ B.t.u. Ir.34 lbs. 50\% sol.

$$
\text { (a) } 105^{\circ}
$$$$
=\mathrm{I}, 667
$$

$$
\overline{3,148}
$$

Heat Balance Around Condenser $H$ :

$$
\text { Heat In }
$$

I lb. vapor
Heat Out

In cooling water $Q_{2}=$ I, 074 B.t.u. I lb. condensate

$$
=\frac{5^{8} \text { B.t.u. }}{\mathrm{I}, \mathrm{I} 3^{2}}
$$

\section{Heat Out}

$2.26 \mathrm{lb}$. vapor @ $40^{\circ} \mathrm{F}$.

$$
=2.26 \times 1,077=2,434 \text { B.t.u. }
$$

I. $26 \mathrm{lb}$. condensate at I0 $5^{\circ} \mathrm{F}$.

$=5^{8}$ B.t.u. $=92$ B.t.u.

Heat absorbed $Q_{4}$ at $T_{4}=2,284$

$$
2,434
$$$$
2,434
$$

Heat Balance Around Absorber F:

\section{Heat In}

20.34 lb. $50 \%$ solution at $105^{\circ} \mathrm{F}$. $=2,990$ B.t.u.

$2.26 \mathrm{lb}$. vapor at $40^{\circ} \mathrm{F} .=2,434$

$$
5,424
$$

Heat Out

$22.6 \mathrm{lb} .45 \%$ solution

$$
\text { (a) } 90^{\circ} \mathrm{F} \text {. }
$$

In cooling water $Q_{3}$

$$
=2,4 \text { I } 8 \text { B.t.u. }
$$$$
=3,006
$$

5,424

Overall Heat Balance for $I$ lb. water evaporated in $C$ : Heat In

$Q_{1}=$ I,800 B.t.u.

Heat Out

$Q_{4}=2,284$

$Q_{2}=$ I,074 B.t.u.

Performance:

4,084

$Q_{3}=3,006$

4,080

$$
\text { C.P. }=\frac{Q_{4}}{Q_{1}}=\frac{2,284}{\mathrm{I}, 800}=\mathrm{I} .27
$$

The importance of the second effect concentrator may be seen by comparing the first two cases given in Table I which summarizes the results of other similar calculations. The addition of the second concentrator as shown in Fig. Io enables the same quantity of heat to concentrate an additional quantity of solution, thereby increasing the coefficient of performance. This is made possible by the greater availability of the heat used at the higher temperatures $\left(260^{\circ} \mathrm{F}\right.$. instead of $162^{\circ} \mathrm{F}$.). 
TABLE I.

Comparison of Solution Cycles for Cooling or Refrigeration of Water.

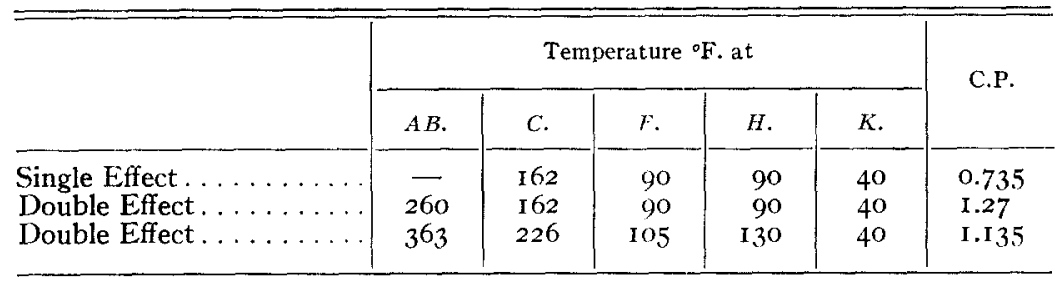

The letters refer to pieces of equipment as identified in Fig. Io.

Although caustic soda solutions have been used in these calculations, other solutions are considered far more satisfactory. Caustic soda causes embrittlement of steel and its use therefore requires nickel or alloys in the fabrication of equipment. Its high viscosity is a serious disadvantage in the heat-transfer and fluid-flow phases of design. Other solutions having the desirable properties of caustic and relatively free from these disadvantages are known, but their thermal properties have not been determined with the completeness or precision with which the thermal properties of caustic soda solutions are known. However the performance of a solution cycle can be estimated within reasonably close limits without the complete and exact knowledge of the heat quantities as given by the enthalpy-concentration chart, Fig. 8 .

The heat input to the cycle depends almost entirely upon the heat required (increase in enthalpy) to vaporize the water from the solution in the first concentrator. This heat quantity is related to the vapor pressure data of the solution through the fundamental thermodynamic equation

$$
\frac{d p}{d T}=\frac{\Delta H}{T\left(V_{v}-\bar{V}_{1}\right)},
$$

in which $\frac{d p}{d T}=$ the slope of the vapor pressure temperature curve,

$T=$ the absolute temperature of the solution, $\Delta H=$ the increase in enthalpy or heat required to vaporize unit weight of solvent from the solution,

$V_{v}=$ the volume of unit weight of solvent vapor, 
$\bar{V}_{1}=$ the partial volume (effective volume) of unit weight of liquid solvent in the solution.

Under ordinary pressure ranges, $\bar{V}_{1}$ is so small compared with $V_{v}$ that $\bar{V}_{1}$ may be neglected without appreciable error.

By writing this equation, Io, for the solution, and also for the pure solvent (usually water) and dividing the latter by the former, the following equation is obtained:

$$
\frac{d T_{S}}{d T_{W}}=\frac{\Delta H_{W} T_{S} V_{S}}{\Delta H_{S} T_{W} V_{W}},
$$

in which $\frac{d T_{S}}{d T_{W}}=$ the slope of the line on the Duhring plot (Fig. 9),

$\Delta H_{W}=$ latent heat of vaporization of solvent from pure liquid solvent to saturated solvent vapor,

$\Delta H_{S}=$ latent heat of vaporization of solvent from solution to superheated solvent vapor at the same pressure,

$T_{W}=$ the boiling point of pure solvent,

$T_{S}=$ the boiling point of solution under the same pressure,

$V_{W}=$ the specific volume of saturated solvent vapor, in equilibrium with pure liquid solvent,

$V_{S}=$ the specific volume of superheated solvent vapor, in equilibrium with solution at the same pressure.

This equation is most useful when written for two different solutions which are compared at the same temperature and pressure, under which conditions the values for $\Delta H_{W}, T_{W}$, and $V_{W}$ are of course the same, and likewise $T_{S}$ and $V_{S}$ are the same. Under these conditions

$$
\frac{d T_{S}}{d T_{W}}=\frac{\Delta H_{W} T_{S} V_{S}}{T_{W} V_{W}} \times \frac{\mathrm{I}}{\Delta H_{S}},
$$

in which $\frac{\Delta H_{W} T_{S} V_{S}}{T_{W} V_{W}}$ is a constant of the same value for the two solutions. 
Therefore the heat required to vaporize the unit weight of solvent vapor from the solution varies inversely as the slope of the Duhring line. By plotting the vapor pressure data of another solution as has been done for caustic soda in Fig. 9, and determining the slope of the line for the two solutions at the same points on the diagram, the latent heat of vaporization of solvent from one solution may be determined from that of the known solution. That solution having the greater slope on the Duhring plot requires less heat for concentration, and similarly gives off less heat on absorption of the low pressure vapor.

When it is considered that many of the thermal quantities within the cycle tend to cancel each other, the external heat balance is not sensitive to small changes in the heat quantities within the cycle. The effect of relatively large differences in specific heat, for example, would be practically eliminated by the heat exchangers used in the cycle. It is therefore possible to determine, on the basis of the vapor pressure data of a solution, the significant heat quantities for determining the ideal thermodynamic efficiency; and by comparison with a similar cycle as computed for sodium hydroxide solutions, to estimate its actual coefficient of performance within reasonably close limits. The available data on a number of promising solutions indicate a slope for the Duhring line not less than that shown for the caustic soda solutions in Fig. 9, and the comparisons herein set forth on the basis of sodium hydroxide solutions are therefore also representative of results to be obtained by the use of other solutes.

Table II compares the energy costs for operation of electrical compressor refrigerators, solution, and steam-jet thermo-compressors of the same duty. Although the coefficient of performance of the electrically driven unit is much higher, the use of low cost heat energy enables the solution thermo-compressor to show more economical operation under present conditions. The C.P. of I.2 used in Table II makes a small allowance from the computed value of 1.27 (Table I) for energy required for pumping solution.

The relatively high charges for energy and cooling water requirements in the case of the steam-jet are partially compensated by the simplicity of equipment, but the much lower 
TABLE II.

Relative Operating Costs for Refrigerating Water to $40^{\circ} \mathrm{F}$. with heat Rejected from the Cycle at $90^{\circ} \mathrm{F}$.

\begin{tabular}{|c|c|c|c|c|c|c|}
\hline & \multirow[b]{2}{*}{$\begin{array}{l}\text { Coeffi- } \\
\text { cient of } \\
\text { Perform- } \\
\text { ance. }\end{array}$} & \multirow[b]{2}{*}{$\begin{array}{l}\text { Relative } \\
\text { Quantity } \\
\text { Energy } \\
\text { Required. }\end{array}$} & \multicolumn{3}{|c|}{ Relative Costs for Energy. } & \multirow[b]{2}{*}{$\begin{array}{c}\text { Relative } \\
\text { Quantity } \\
\text { Cooling } \\
\text { Water } \\
\text { Required. }\end{array}$} \\
\hline & & & $\begin{array}{c}\text { Coal @ } \\
\$ 5 / \text { ton } \\
\text { Electricity } \\
\$ 0.0125 \\
\text { KW.Hr. }\end{array}$ & $\begin{array}{l}\$ 4.40 / \text { ton } \\
\$ 0.0125 \\
\text { KW.Hr. }\end{array}$ & $\begin{array}{l}\text { \$14.I5/ton } \\
\text { \$0.0Io } \\
\text { KW.Hr. }\end{array}$ & \\
\hline $\begin{array}{l}\text { Electrical Com- } \\
\text { pressor........ } \\
\text { Double Effect So- } \\
\text { lution Compres- }\end{array}$ & $4: 7$ & I.OO & I.0O & I.OO & 1.00 & 1.00 \\
\hline Steam Jet Com. & $\mathrm{I} .2$ & 3.92 & 0.284 & .25 & 1.00 & I.5 I* \\
\hline pressor....... & 0.3 & I 5.7 & I. 136 & 1.00 & 4.00 & $3.6 \mathrm{r}$ \\
\hline
\end{tabular}

Coal assumed to have heating value of 13,500 B.t.u. and used with furnace efficiency of 70 per cent.

* This is a maximum value assuming isothermal rejection of heat. Actually the solution cycle rejects heat over a temperature range and the cooling water is heated to a higher temperature so that this figure in practice may be easily reduced to about 0.85 .

operating costs of the double effect solution cycle appear favorable.

Under some conditions the quantity of cooling water required is a serious consideration in operating costs. If the cooling water is passed through the absorber and then the condenser as shown in Fig. Io, and more concentrated solutions used (such as 55 per cent. and 60 per cent.), the cooling water may be heated to a higher temperature and its quantity greatly reduced with only a small loss in the coefficient of performance (as indicated by the third line in Table I). As the concentration of the solutions is easily changed by modifying operating conditions, the solution thermo-compressor is flexible both as to changes in capacity with constant cooling water and to changes in cooling water at constant capacity by increased evaporation in the concentrator.

The low maximum pressure required for efficient operation of solution refrigerating cycles, less than atmospheric for the first two cases and only 2 atmospheres for case three of Table $I$, is an important advantage for many uses. 
The capacity of a given steam-jet compressor, that is, the pounds of water vapor drawn in and compressed at fixed pressure, is approximately constant regardless of the amount of steam being used. Therefore flexibility in capacity is obtained by using a number of jets in parallel with manual or automatic control. If cooling water temperature rises the jet will fail, or strike back, until the suction pressure is correspondingly raised by increase in temperature of refrigerated water, unless the pressure of steam supply is increased. Steam-jet installations should have reserve steam pressure for increased cooling water temperature and consist of multiple jets in parallel for variation in capacity.

The solution compressor is readily adjusted to decreased loads, and increased steam pressure or temperature in the concentrator is all that is necessary to compensate for increased temperature of cooling water (case 3 Table I).

Mechanical compressors may be adjusted for decreased load but will not refrigerate the water to the desired temperature if the temperature of the cooling water rises beyond that for which the unit is designed.

In general there appear to be three fields in which the use of solution cycles may prove desirable. The most promising at present is probably for refrigeration, as for air conditioning and possibly the reversal of this operation for the purpose of heating buildings.

As a steam pressure transformer, the use of solutions appears promising in many cases. It is possible that future developments may indicate the use of such cycles for the generation of power. Simple cycles as were used by Honigmann are not economical and intensive development will be required before solutions may be employed advantageously in competition with the common means of generating power.

In the case of air conditioning, heating, and for the compression of vapors, advantages of low operating cost are indicated for the use of the solution cycle. Further engineering development and the use of non-corrosive solutions, now being studied, will reduce the original cost of solution cycle equipment so that the total savings in operation may be large, particularly in installations of moderate to large capacity. The peculiar advantage in the storage of available energy voL. 2I9, NO. I3I2-30 
in the form of concentrated solution and pure solvent may hasten the application of the use of solutions in the generation of power where wide fluctuations in load may be expected.

The theoretical basis for the computation of such cycles is now well established, equipment can now be designed and performance computed. It is expected that engineering development will soon follow, making possible the practical application of the use of such solution cycles with the corresponding gain in operating economy.

\section{BIBLIOGRAPHY.}

I. Bošnjaković, Z. Ver. deut. Ing., 75, I I97 (I931).

2. D'Equevilley-Montjustin, U.S. Patent 986,373, Mar. 7, I9Ir.

3. Faraday, M., Ann. de Chimie et de Physique, 20, series 2, p. 320 (1822).

4. Honigmann, M., U. S. Patent 337,062, March 2, I 886.

4a. Honigmann, M., U. S. Patent 340,7 I8, April 27, 1886.

5. Keenan, "Steam Tables and Mollier Diagram," American Society of Mechanical Engineers, New York, 1930.

6. Koenemann, E., British Patent 178,829, January 4, 1923; U. S. Patent I,687,94I, October 16, I928.

7. Lamm, Emile, "Improvement in Chloride-of-Calcium Engines," U. S. Patent 124,594, March 12, I872.

8. Marks, Lionel S., Mech. Eng., 49, 600 (June 1927).

9. Merkel, Frederick, Z. Ver. deut. Ing., 72, I09 (1928); Mech. Eng., 50, 3I4 (April 1928); Z. Ges. Kälte-Ind., 35, I30 (1928); Arch. Warmewirt, 10, I3 (I929), and Bosnjakovic, "Diagramme und Tabellen zur Berechnung der Absorption-Kältemaschinen," Julius Springer, Berlin (I929).

Io. McCabe, Warren L., "Enthalpy Concentration Chart," Trans. American Institute Chemical Engineers, 3 I (I934).

I I. Pape, Wilhelm, German Pat. 317,928, January 8, 1920.

I2. Ramsay and Young, Phil. Mag. (5), 20, p. 515 (1885).

I3. Riedler, A., Z. Ver. deut. Ing., 27, 729 (Nov. 1883).

14. Schneevogl, M., French Patent 384,222, January 29, 1908.

I5. Sellew, Wm. H., Trans. American Institute Chemical Engineers, 30, 546 (I934).

I6. Selvey, A. M., Trans. American Institute Chemical Engineers, 30, 567 (I 934).

I7. Spence, Engineering, p. I24 (February I3, I874). 